\title{
Similarity and dissimilarity of joint interface morphology in magnetic pulse welded $\mathrm{Al} / \mathrm{Cu}$ and $\mathrm{Al} / \mathrm{Ni}$ plates
}

\author{
Shingo Kimura ${ }^{1 *}$, Shinji Muraishi ${ }^{2}$, and Shinji Kumai ${ }^{2}$ \\ ${ }^{1}$ Graduated student, Tokyo Institute of Technology, 2-12-1, Ookayama, Meguro-ku, Tokyo, Japan \\ ${ }^{2}$ Tokyo Institute of Technology, Department of Materials Science and Engineering, 2-12-1, Ookayama, Meguro-ku, Tokyo, Japan
}

\begin{abstract}
A characteristic wavy morphology often appears at the joint interface of magnetic pulse welding (MPW), and an intermediate layer is formed in some metal combinations. It has been known that the wavy morphology changes mainly depend on the density difference between the metals. A sinusoidal wavy interface is formed for the combination of similar metals $(\mathrm{Al} / \mathrm{Al}, \mathrm{Cu} / \mathrm{Cu})$ and that of dissimilar metals having almost the same density $(\mathrm{Cu} / \mathrm{Ni})$. In contrast, a trigger-like wavy interface is formed for the combination having a large density difference $(\mathrm{Al} / \mathrm{Cu}, \mathrm{Al} / \mathrm{Fe})$. The difference in strength (hardness) of the solid metal is also assumed to affect the wavy interface morphology. In the present study, two metal combinations $(\mathrm{Al} / \mathrm{Cu}$ and $\mathrm{Al} / \mathrm{Ni})$ were subjected to the MPW to elucidate the effect of hardness difference, since $\mathrm{Cu}$ and $\mathrm{Ni}$ have almost the same density, but different hardness. Both the MPWed $\mathrm{Al} / \mathrm{Cu}$ and $\mathrm{Al} / \mathrm{Ni}$ joints showed a trigger-like wave interface. The wave size (wave-height and wavelength) of $\mathrm{Al} / \mathrm{Ni}$ was smaller than that of $\mathrm{Al} / \mathrm{Cu}$. In $\mathrm{Al} / \mathrm{Ni}$, the distribution of intermediate phase was more continuous tracing the outline of the wave. The numerical simulation of the wave formation process was performed using the Smoothed Particle Hydrodynamics (SPH) method. It was revealed that the extent of metal jet penetration into the metal in the process of joining behind the collision point was weaker in $\mathrm{Ni}$ than in $\mathrm{Cu}$. This is considered to be due to the larger deformation resistivity of $\mathrm{Ni}$, which is harder than that of $\mathrm{Cu}$.
\end{abstract}

\section{Introduction}

Resent years, demand for dissimilar metal joints is increasing in many fields like automobile or electronic devices. Solid-state welding, which does not include melting phenomenon at the joint interface, has been gaining more attention recently.

Impact welding is one of the high-speed solid-state welding methods which can establish strong bonding even in the dissimilar metal combination. In impact welding, a characteristic wavy morphology often appears at the joint interface. An intermediate layer forms in some metal combinations. It has been known that the wavy morphology changes mainly depending on the density difference between the metals. A sinusoidal wavy interface is formed for the combination of similar metals $(\mathrm{Al} / \mathrm{Al}, \mathrm{Cu} / \mathrm{Cu})$ and that of dissimilar metals having almost the same density $(\mathrm{Cu} / \mathrm{Ni})$ (Fig. 1 (a), (b)). In contrast, a trigger-like wavy interface is formed for the combination having a large density difference $(\mathrm{Al} / \mathrm{Cu}$ (Fig. 1 (c)), $\mathrm{Al} / \mathrm{Fe}$ ). In impact welding, it is said that the solid metal around the collision point acts like a fluid due to the extremely high pressure caused by impact. Therefore, the wavy interface morphology is said to be affected by mainly the density which is determined by the fluid's characteristics. However, the difference in strength (hardness) of the solid metal is also assumed to affect the (a)

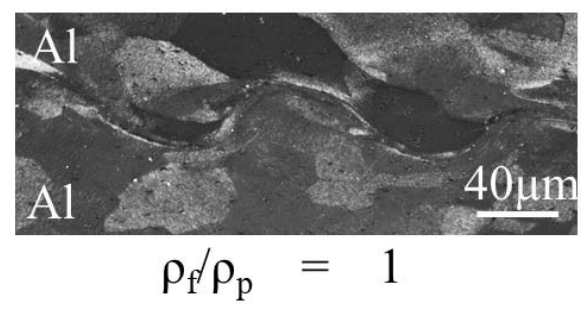

(b)

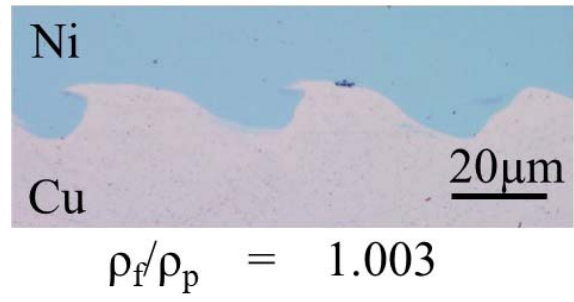

(c)

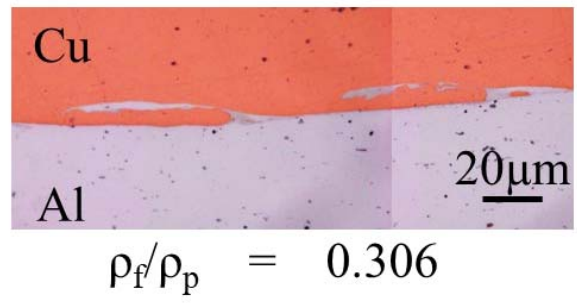

Fig. 1. The joint interface morphology in different density ratio (a) $\mathrm{Al} / \mathrm{Al}$, (b) $\mathrm{Cu} / \mathrm{Ni}$ and (c) $\mathrm{Al} / \mathrm{Cu}$ fabricated by MPW. ( $\rho_{\mathrm{f}}$ : density of flyer plate, $\rho_{\mathrm{p}}$ : density of parent plate.)

\footnotetext{
* Corresponding author: kimura.s.aj@m.titech.ac.jp
} 
wavy interface morphology.

Magnetic pulse welding (MPW) is one of the impact welding methods which uses electromagnetic force to accelerate and collide two metals together for joining. MPW is used for joining of thin plates or pipes [1]. In the present study, two metal combinations $(\mathrm{Al} / \mathrm{Cu}$ and $\mathrm{Al} / \mathrm{Ni}$ ) were subjected to the MPW to elucidate the effect of hardness difference on the joint interface morphology, since $\mathrm{Cu}$ and $\mathrm{Ni}$ have almost the same density, but different hardness.

\section{Experimental procedure}

Bmax MP12.5/25 with capacitance $40 \mu \mathrm{F}$ was used for MPW. Fig.2 shows a schematic diagram of the experimental setup. A pure $\mathrm{Al}$ plate (hereafter $\mathrm{Al}$, $200 \mathrm{~mm} \times 70 \mathrm{~mm} \times 0.8 \mathrm{~mm}$ ) was used as a flyer plate and a pure $\mathrm{Cu}$ and $\mathrm{Ni}$ plate (hereafter $\mathrm{Cu}$ and $\mathrm{Ni}, 200 \mathrm{~mm} \times$ $70 \mathrm{~mm} \times 0.4 \mathrm{~mm}$ ) were used as a parent plate to fabricate $\mathrm{Al} / \mathrm{Cu}$ and $\mathrm{Al} / \mathrm{Ni}$ joint. The initial surface condition was as-received and quite smooth, which underwent cold rolling, so no surface treatment was added. The flyer plate's overlap length over the coil has an important role in MPW [2]. In this study, the overlap length is fixed to $3 \mathrm{~mm}$ which is equal to the upper side width of coil. The experimental conditions performed in the present study are shown in Table 1. In both combinations, the surface of metal plate was cleaned by acetone before MPW in order to eliminate the effect of surface contamination.

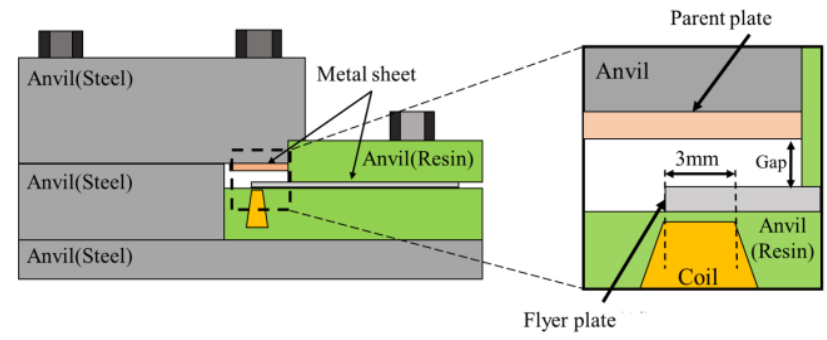

Fig. 2. Schematic diagram of experimental setup.

Table 1. Experimental Condition

\begin{tabular}{|c|c|c|c|}
\hline Parent plate & $\begin{array}{c}\text { Hardness of } \\
\text { parent plate } \\
\text { (HV) }\end{array}$ & $\begin{array}{c}\text { Charging } \\
\text { energy (kJ) }\end{array}$ & Gap (mm) \\
\cline { 1 - 2 } $\mathrm{Cu}$ & 76.9 & \multirow{2}{*}{4} & 2.4 \\
\cline { 1 - 2 } $\mathrm{Ni}$ & 181 & & \\
\hline
\end{tabular}

After MPW, the joint interface was observed by using an optical microscope and SEM.

\section{Numerical analysis method}

A series of numerical analyses were performed in order to investigate the interface forming behaviour of both combinations. The analysis was divided into two steps including (1) high-speed oblique collision process caused by electromagnetic force and (2) wavy interface formation process. The numerical analysis models described below are mainly based on the model reported by Kambe et al. [3].

\subsection{Deformation manner of the flyer plate and impact angle and velocity analysed by ANSYS Emag-mechanical}

In the first step, the magnetic field and deformation manner of the Al plate by electromagnetic force were reproduced by ANSYS Emag-mechanical, which uses the finite element method (FEM) to simulate a situation. Fig. 3 shows the FEM model used in this step. The left side shows a FEM circuit which calculates the current runs through the coil. After the calculation of the current, magnetic flux generated around the coil was calculated with the FEM model shown in the right side of Fig.3. Then, the induced electromagnetic force was calculated, and the deformation manner of the metal plates was reproduced. Finally, the impact velocity and impact angle were obtained from the simulation result.

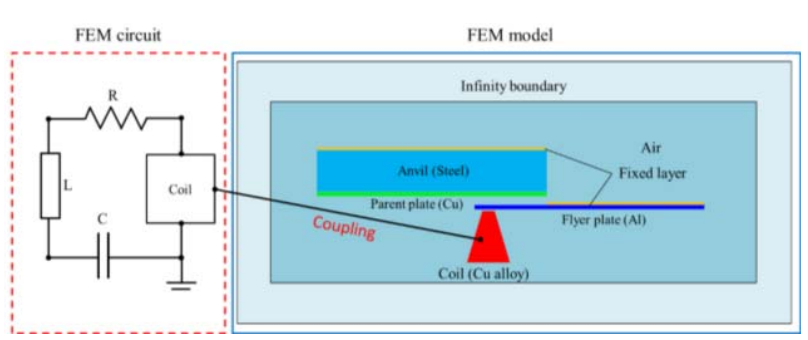

Fig. 3. The FEM model used for ANSYS Emag-mechanical.

\subsection{The metal jet emission and the wavy interface formation analyzed by ANSYS Autodyn}

In the next step, the collision process including the metal jet emission and wavy interface formation behaviour was reproduced using the smoothed particle hydrodynamics (SPH) method. In this method, materials are discretized into particles which defined as interpolated points of physical quantities. The particles are distributed at a specific distance defined as the smoothing length, $h$. Since there is no limitation of mesh shape deformation, this method is suitable for large deformation problems like MPW. Fig.4 shows the model used for this step. The smoothing length was set to $1 \mu \mathrm{m}$ near the surface and gradually increased as going away from the surface in order to reduce the calculating time. This analysis aims at reproducing the metal jet emission and the wavy interface formation. The impact velocity and the impact 
angle obtained by the first step simulation were used for the analysis.

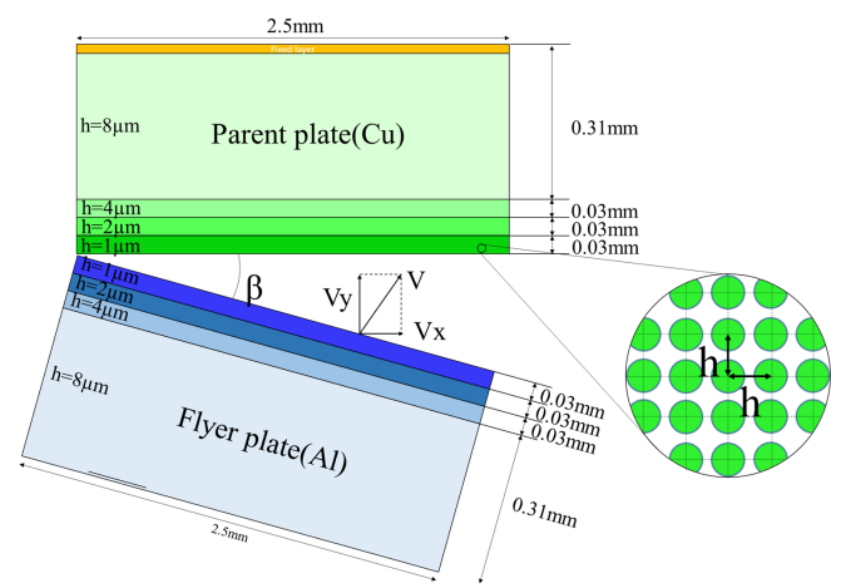

Fig. 4. The Simulation model for SPH analysis.

\section{Results and discussion}

Fig. 5 shows the obtained interface morphology of each combination. In MPW, the impact velocity and impact angle change through the collision process and these conditions dominate the wavy morphology [4]. To compare the wavy interface formed at the same impact velocity and angle conditions, these pictures were taken from the same distance from the initial impact point. Both joint interfaces showed a trigger-like wavy morphology and contained the intermediate layer. The wave size of $\mathrm{Al} / \mathrm{Ni}$ was smaller than that of $\mathrm{Al} / \mathrm{Cu}$, and the shape of the wave was more clearly observed in $\mathrm{Al} / \mathrm{Cu}$ than $\mathrm{Al} / \mathrm{Ni}$. In addition, the distribution of the intermediate layer was formed more continuously tracing the outline of the wave.

(a)
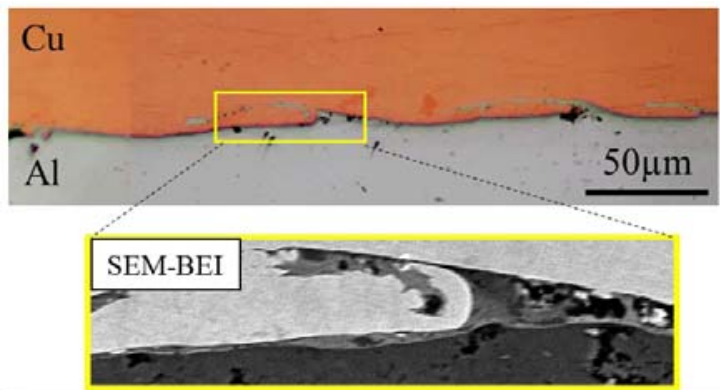

(b)

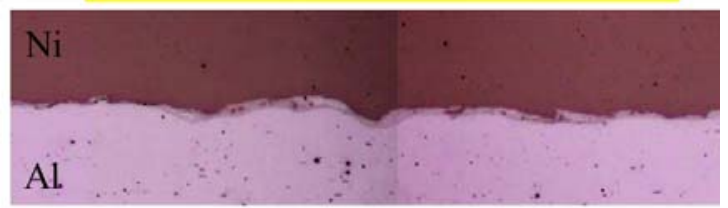

Fig. 5. The joint interface morphology of (a) $\mathrm{Al} / \mathrm{Cu}$, (b) $\mathrm{Al} / \mathrm{Ni}$

Fig. 6 shows the reproduced wavy interface morphology by using the SPH method. Both interfaces showed a trigger-like wavy morphology and the wave size was smaller in the $\mathrm{Al} / \mathrm{Ni}$ interface. These results show a good correspondence with the experimental results. Fig. 7 shows the wavy interface formation behaviour reproduced by the SPH method. In this figure, the particles with different colors were used to locate the particles position from the surface in order to detect the material movement at the joint interface in detail. The metal jet emission was reproduced as the SPH particle emission from the collision point. The metal jet was emitted mainly from the Al surface in both combinations. As the collision proceeded, a part of the metal jet penetrated

(a) $\mathrm{Cu}$

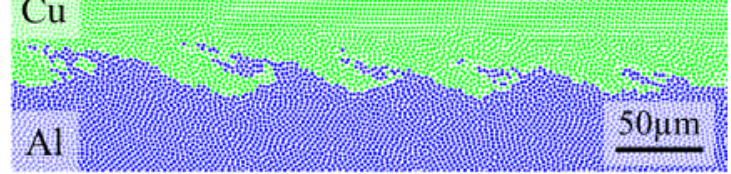

(b)

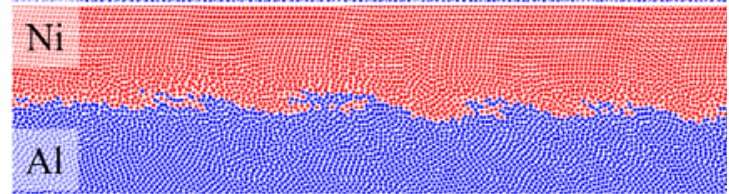

Fig. 6. The reproduced joint interface morphology of (a) $\mathrm{Al} / \mathrm{Cu}$, (b) $\mathrm{A} 1 / \mathrm{Ni}$

into the parent material (indicated by a red arrow) and the rest of metal jet continued emitting forward. In the case of $\mathrm{Al} / \mathrm{Cu}$, the penetration became deeper and the wave continued growing after the collision point passed. On the other hand, the penetration was weakened, and the wave did not grow much in the case of $\mathrm{Al} / \mathrm{Ni}$. Due to the growth of the wave, a swirling motion occurred in $\mathrm{Al} / \mathrm{Cu}$. This is considered to be due to the hardness difference of the parent material. The metal jet could not penetrate much into the $\mathrm{Al} / \mathrm{Ni}$ because the deformation resistivity of $\mathrm{Ni}$ is larger than that of $\mathrm{Cu}$.

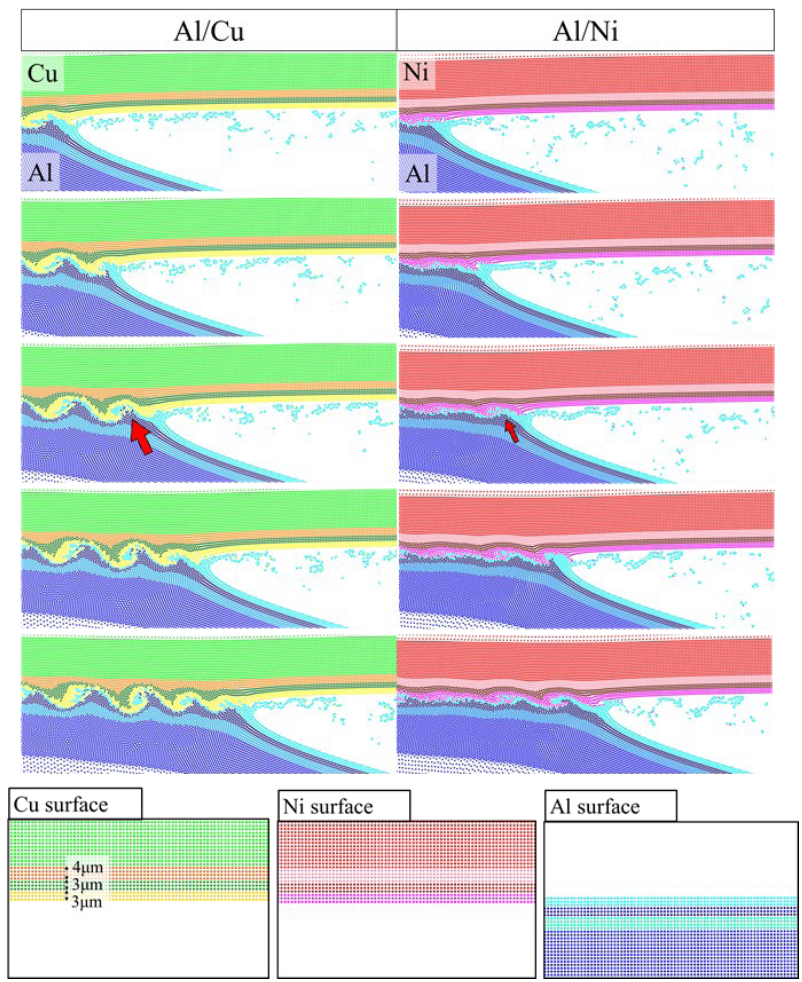

Fig. 7. The joint interface formation behaviour of $\mathrm{Al} / \mathrm{Cu}$ and $\mathrm{Al} / \mathrm{Ni}$ reproduced by SPH method. 
Fig. 8 shows the temperature distribution and the area above the melting temperature, in which the local melting is assumed, reproduced by using the SPH method. From Fig. 8 (a), a significant temperature rise occurred at the joint interface, especially at the location where the metal jet penetration occurred. In Fig. 8 (b), the red area consisting of red particles indicate that exceeding the melting point, which may result in the formation of intermediate layer in the successive cooling process. In $\mathrm{Al} / \mathrm{Cu}$, the distribution of the red area was not continuous and separated from wave to wave. On the other hand, the distribution of the red area was continuous along the interface in $\mathrm{Al} / \mathrm{Ni}$. The trace of the red area (Fig. 8) showed good agreement with the trace of the intermediate layer formed at the MPWed $\mathrm{Al} / \mathrm{Cu}$ and $\mathrm{Al} / \mathrm{Ni}$ joints (Fig. 5).

(a)

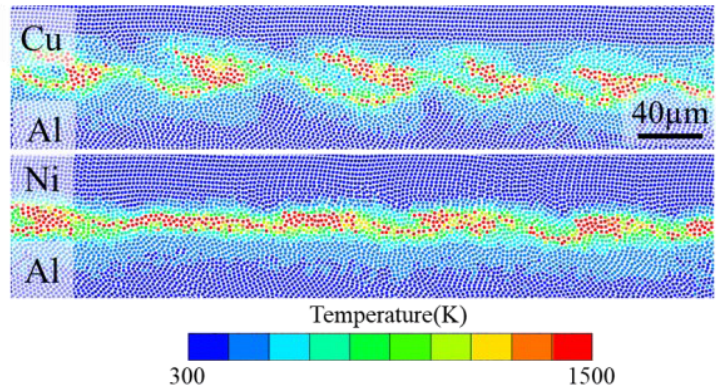

(b)

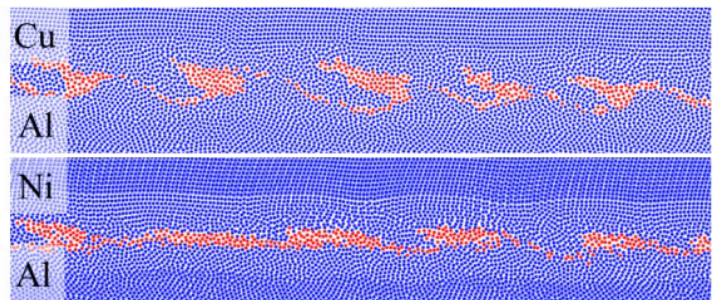

Fig. 8. The temperature distribution (a) and possible local melting zone distribution (b) of reproduced joint interface.

\section{Conclusions}

Magnetic pulse welding for two combination, $\mathrm{Al} / \mathrm{Cu}$ and $\mathrm{Al} / \mathrm{Ni}$, were performed. Both joint interfaces showed trigger-like wavy morphology, and the wave size was smaller in $\mathrm{Al} / \mathrm{Ni}$ combination. The distribution of intermediate layer was formed more continuously tracing the outline of the wave. Numerical analyses were performed to reproduce the wavy interface formation behaviour by using SPH method. The analysis successfully reproduced the wavy interface formation behaviour. The metal jet emission reproduced the emission of SPH particles, and the metal jet was mainly composed of $\mathrm{Al}$ particles in both combinations. The wavy interface was formed due to the penetration of the metal jet into the parent material. In the case of $\mathrm{Al} / \mathrm{Ni}$, the penetration of the metal jet into the parent material was weaker than in the case of $\mathrm{Al} / \mathrm{Cu}$, so a smaller wavy interface was formed for $\mathrm{Al} / \mathrm{Ni}$. This is considered to be due to the difference in hardness of the parent material.

\section{Acknowledgement}

A part of the present work was supported by JSPSKAKENHI (JP19K05028) and the scholarship from the Light Metal Educational Foundation. Their supports are deeply acknowledged.

\section{Appendices}

The parameters used in this study is shown in the table below. The Mie-Grüneisen EOS based on the shock Hugoniot was applied for the materials in this study. The constitutive model used for this study was the SteinbergGuinan constitutive model, which represents the mechanical behavior of metals. [3]

Table. 2 parameters used for numerical analysis

\begin{tabular}{|c|c|c|c|c|}
\hline Symbol & $\begin{array}{l}\text { Material } \\
\text { property }\end{array}$ & $\mathrm{Al}$ & $\mathrm{Cu}$ & $\mathrm{Ni}$ \\
\hline$\rho$ & $\begin{array}{c}\text { Density /g } \\
\mathrm{cm}^{3}\end{array}$ & 2.707 & 8.930 & 8.900 \\
\hline$\Gamma$ & $\begin{array}{l}\text { Guruneisen } \\
\text { coefficient }\end{array}$ & 1.97 & 2.02 & 1.93 \\
\hline$c_{0}$ & $\begin{array}{l}\text { Bulk sound } \\
\left.\text { speed } / \mathrm{m} \cdot \mathrm{s}^{-1}\right)\end{array}$ & 5386 & 3940 & 4650 \\
\hline$s$ & Parameter S1 & 1.339 & 1.489 & 1.445 \\
\hline$C_{\mathrm{v}}$ & $\begin{array}{l}\text { Specific heat } \\
/ \mathrm{J} \cdot \mathrm{kg}^{-1} \cdot \mathrm{K}^{-1}\end{array}$ & 884 & 383 & 401 \\
\hline$G_{0}$ & $\begin{array}{l}\text { Initial shear } \\
\text { modulus /GPa }\end{array}$ & 27.1 & 47.7 & 85.5 \\
\hline$Y_{0}$ & $\begin{array}{l}\text { Initial yield } \\
\text { stress / GPa }\end{array}$ & 0.04 & 0.12 & 0.14 \\
\hline$Y_{\max }$ & $\begin{array}{c}\text { Maximum } \\
\text { yield stress } \\
/ \mathrm{GPa} \\
\end{array}$ & 0.48 & 0.64 & 1.2 \\
\hline$\beta$ & $\begin{array}{c}\text { Hardening } \\
\text { constant }\end{array}$ & 400 & 36 & 46 \\
\hline$n$ & $\begin{array}{c}\text { Hardening } \\
\text { exponent }\end{array}$ & 0.27 & 0.45 & 0.53 \\
\hline$G_{\mathrm{P}}^{\prime}$ & $\begin{array}{c}\text { Derivative } \\
\mathrm{dG} / \mathrm{dP}\end{array}$ & 1.767 & 1.350 & 1.393 \\
\hline$G^{\prime}{ }_{\mathrm{T}}$ & $\begin{array}{c}\text { Derivative } \\
\mathrm{dG} / \mathrm{dT} / \mathrm{GPa} \text { - } \\
\mathrm{K}^{-1}\end{array}$ & $\begin{array}{c}-0.01 \\
669\end{array}$ & $\begin{array}{c}-0.01 \\
798\end{array}$ & $\begin{array}{c}-0.02 \\
783\end{array}$ \\
\hline$Y_{\mathrm{P}}^{\prime}$ & $\begin{array}{l}\text { Derivative } \\
\mathrm{dY} / \mathrm{dP}\end{array}$ & $\begin{array}{c}0.002 \\
608\end{array}$ & $\begin{array}{c}0.0033 \\
96\end{array}$ & $\begin{array}{c}0.002 \\
282\end{array}$ \\
\hline
\end{tabular}




\section{References}

1. T. Aizawa, J. Japan Inst. Light Met. 54, (2004), pp153-158

2. Z. Lu, W. Gong, S. Chen, T. Yuan, C. Kan, X. Jiang, J. Manu. Proc. 46, (2019), pp59-66

3. T. Kambe, Y. Kedo, S. Muraishi, S. Kumai, Mater. Trans. 61 (2020), pp346-354

4. M. Watanabe, S. Kumai, Mater. Trans. 50, (2008), pp286-292 